\title{
Trends And Challenges Of Public Health Care Financing System In Nigeria: The Way Forward.
}

\author{
Yunusa, U. ${ }^{\mathrm{a}}$, Irinoye, O. ${ }^{\mathrm{b}}$, Suberu, A. ${ }^{\mathrm{a}}$, Garba, A., M. ${ }^{\mathrm{c}}$, Timothy, G. ${ }^{\mathrm{d}}$, Dalhatu, \\ A. $^{\text {e }} \&$ Ahmed, $S$. \\ 1Department of Nursing Sciences, Bayero University, Kano \\ 2Department of Nursing Sciences, Obafemi Awolowo University, Ile Ife \\ 3 College of Nursing and Midwifery Sciences Sokoto. \\ 4College of Nursing and Midwifery, Yola Adamawa state. \\ 5Department of Nursing Sciences, General Hospital, Funtua \\ 6Department of Nursing Sciences, Federal Neuro-psychiatric Hospital, Kware, Sokoto
}

\begin{abstract}
One of the basic functions of government is to provide quality and effective health care services to its citizens as it is only when the people are healthy that any reasonable development can take place. Funding of health care sector in Nigeria is still face with enormous challenges that must be overcome if quality and effective health care service is to be made available to the people. This article reviewed relevant literatures related to public health care financing in Nigeria which were published by journals within and outside the country. An overview of the literatures showed that public health care services in Nigeria is financed through; out-of-pocket payments, tax revenue, donor funding and through health insurance. Trends have shown that the bulk of public health care is financed by households through out-of-pocket payments with government contributing just about $25 \%$ of the total health expenditure. The major challenges of health care financing includes, poor funding by government, high out of pocket payment, inadequate implementation of health care financing policy and corruption. This article concluded by recommending that there should be an increase in government funding of public health care, adequate implementation of health care policies, proper monitoring and evaluation of utilization of funds, discourage government sponsorship for treatment of personnel abroad and finally encouraging local production of drugs and other medical equipments.
\end{abstract}

Keywords: Trends, Challenges, Public Health, Financing, Nigeria

\section{Introduction}

One of the basic functions of government in any country is to provide quality and effective health care services to its citizens. For the health care services to be effective and efficient, it must be adequately funded, and the fund must be adequately utilized devoid of fraud and corruption. Funding of health care sector in Nigeria is still face with enormous challenges that must be overcome if quality and effective health care services is to be made available to the people. The health of people in country directly affects the development of the country. This is because according to the World Health Organization (WHO, 2005) 50\% of economic growth differentials between developed and developing nation is attributable to ill health and low life expectancy. So for a country to be developed, it has to spend a high proportion of its Gross Domestic Product (GDP) on health care. It is in this view that the constitution of Nigeria states in section 17(3)(c) and (d) states that "the state shall direct its policy towards ensuring that the health, safety and welfare of all persons in employment are safeguarded and not endangered or abused and that the state shall direct its policy towards ensuring that there are adequate medical and health facilities for all persons"

Healthcare financing refers to strategies for paying for healthcare expenditures. Having known that there is a positive relationship between health and economic growth, then for any economy to develop, it must commit sufficient expenditure to health to achieve desired levels of health status and economic development (Agbatogun \& Taiwo, 2010). Another thing that is well known is that ill-health is a major cause of poverty (Agbatogun \& Taiwo, 2010). International literature identifies three sources of health financing-public, quasipublic and private sources. However, there are substantial variations across countries in the manner in which revenue is raised from these sources and the relative weight of each in the overall finance of healthcare (Ichoku \& Fonta , 2009). In Nigeria, health care is financed through; Tax revenues, out of pocket payments (user payment), health insurance (social and community based insurance), donor funding, exemptions and deferrals, and subsidies (Savedoff, 2004)( Olakunde, 2013) (Uzochukwu, 2013).

The Nigerian health system has been rated poorly in health care financing over the years. For example household out-of-pocket expenditure as a proportion of total health expenditure averaged 64.5\% between 1998 and 2002. This indicates that the burden of health expenditure is very high on households. Hence the need to 
explore and improve other sources of financing that are efficient, fair and sustainable (Federal Republic of Nigeria FRN, 2006). This have affected health care delivery in country as the 2008 country's indicators shows that there was 630 maternal deaths per 100,000 live births, and an under five mortality rate of 124 deaths per 1000 live births. Although Nigeria has seen a 38\% reduction of infant mortality rate to 78 deaths per 1,000 live births in 2012, Nigeria still comprises a large share of the world's burden of child and maternal morbidity and mortality (Federal Ministry of Health FMoH, 2014).

\section{Public Health Care System In Nigeria}

Public health care in Nigeria is provided in three levels; the primary, secondary and tertiary all of which are managed by the local, state and federal governments respectively. Primary health centers are the first point of contact for patients, providing preventive, curative, health promoting and rehabilitative services. At the secondary care level, patients are referred for specialized services from the primary health care level, through out-patient and inpatient services of hospitals for general medical, surgical, paediatrics, obstetrics, gynaecology and community health services. The tertiary level is the apex health care system in Nigeria consisting of teaching hospitals, federal medical centers and other specialist hospitals which provide care for specific disease conditions or specific groups of patients. In Nigeria, many secondary and tertiary health facilities are crowded with patients that have simple ailments that can be managed at the primary health centers which typically have many idle health care workers. However, there are some services that should be provided at all levels of care such as immunization, antenatal care and family planning (The Nigerian academy of science, 2009). Although the local governments have the main responsibility of managing the Primary Health Care PHC, all the three tiers of government and various agencies participate in the management of the PHC. This at times results in duplication, overlap, and confusion of roles and responsibilities (World Bank, 2010)

\section{Public Health Care Finance System In Nigeria}

Health care financing refers to the collection of funds from various sources (example; government, households, businesses, and donors) pooling them to share financial risk across larger population groups and using them to pay for services from public and private health care providers. The objectives of health care financing are to make funding available, ensure appropriate choice and purchase of cost-effective interventions, give appropriate financial incentives to providers and ensure that all individuals have access to effective health services, achieving equity and efficiency in use of healthcare spending, ensure that essential healthcare goods and services are adequately provided for, ensure that the money is spent wisely so that the Millennium Development Goals MDGs could be achieved (Uzochukwu, 2013) (Soyibo et al, 2005). The major sources of finance for the health sector in Nigeria are the three tiers of government (Federal State and Local Government), public general revenue accumulated through various forms of taxation, the health insurance institutions (private and public), the private sector (firm and households), donors and mutual health organizations (Soyibo et al, 2005).

Selection of an adequate and efficient method(s) of financing in addition to organizational delivery structure for health services is essential if a country is set to achieve its national health objective of providing health for all (Carrin, Evans \& Xu , 2007).Nigeria as county has developed several policies and strategies to ensure that the health care sector is adequately financed (Uzochukwu, 2013). These policies are to serve as guide to the way government allocate and effectively manage fund in the health care sector. The Nigerian policies and plans for addressing health care financing includes; The National Health policy, Health Financing policy, National Health Bill and the National Strategic Health Development Plan (National Health Plan) 2010 2015 (Uzochukwu, 2013). The National Assembly passed the National Health Bill on March 22, 2014. The objective of the National Health Policy is to strengthen the national health system such that it would be able to provide effective, efficient, quality, accessible and affordable health services that will improve the health status of Nigerians. It prescribed the development of a National Health Financing Policy, as one of the means of achieving accessible, sustainable, affordable, equitable and efficient health care delivery. (Federal Republic of Nigeria FRN, 2006).

\section{Health Care Financing Options in Nigeria. i.Tax Revenue}

This is a health financing system where government revenues are the main source of health care expenditure (Savedoff, 2004). Public health facilities in Nigeria are financed primarily by the public through tax revenue. The federally collected revenue consist of crude oil and gas export proceeds, petroleum profit tax, royalties and the related proceeds of domestic crude oil sales/other oil revenues, companies' income tax, customs and exercise duties, value-added tax (VAT), tax on petroleum products, education tax, and other items of independent revenues to the federal government. (Obansa \& Orimisan, 2013) 
The results of study by Agbatogun \& Taiwo, (2010) showed that Gross Domestic Product GDP is the most important determinant of health allocation. The total government health expenditure as a proportion of Total Health Expenditure (THE) was estimated as $18.69 \%$ in 2003, 26.40\% in 2004, and 26.02\% in 2005 (Soyibo, Olaniyan \& Lawanson, 2009) Federal government capital expenditure on health has not been significant over the years. In the Abuja Declaration which Nigeria and 43 other African countries signed, in 2001, they committed themselves to spending $15 \%$ of their annual budgets on public health, but this has not been achieved over the years as the Nigerian government continues to pay leap service to the funding of the nation's health services system. (Obansa \& Orimisan, 2013). Remarkably, the federal budgetary component of health expenditure has increased over the years. It increased from 1.7\% in 1991 to $7.2 \%$ in 2007 (WHO, 2009, Nigerian Health System, 2011). Nevertheless, the budgetary allocation for health is still below the $15 \%$ signed by the Nigerian government in the Abuja declaration (WHO, 2009). Nigeria spends less than 5\% of their gross domestic product (GDP) on health, and annual per capita health spending is less than US\$ 35 proposed by Commission on Macroeconomics and Health (FRN, 2006).

\section{ii. Out of Pocket Payment}

Out-of-pocket payments are payments made directly by a patient to a health service provider without reimbursement. This involves payment for health care at the point of service. The charges levied for health care services are referred to as user fees. The scope of user fees is quite variable and can include any combination of drug costs, medical material costs, entrance fees, and consultation fees. (Lagarde \& Palmer, 2006). Evidence indicates that private health spending accounts for about $64 \%$ of total health expenditure and could be more than US\$ 23 per capita. The results provide evidence on the impoverishing effect of healthcare payments on households. On average, about $4 \%$ of households are estimated to spend more than half of their total household expenditures on health care and $12 \%$ of them are estimated to spend more than a quarter (FRN, 2006). Out-ofpocket payments account for the highest proportion of health expenditure in Nigeria. Out-of-pocket expenditure as a proportion of THE averaged 64.59\% from 1998 to 2002 (Soyibo, 2009). In 2003, it accounted for 74\% of THE. It decreased to $66 \%$ in 2004 and later increased to $68 \%$ in 2005 (Soyibo et al, 2009). This implies that households bear the highest burden of health expenditure in Nigeria.

\section{iii. Donor Funding}

This is the means of financing health care by external agencies and nongovernmental organization such as the World Health Organization, World Bank and United Nations Children Fund. The annual average official development assistance inflow from 1999 to 2007 was estimated at US\$ 2.335 and US\$4.674 per capita, respectively (United Nations Development Program UNDP, 2011). These figures are way below the SubSaharan African average of US\$28 per capita (7.57). The contribution of development aid to health care financing in Nigeria was estimated as N27.87 billion (4\% of THE) in 2003. This increased by $29 \%$ to N36.04 billion (4.6\% of THE) in 2004 and by just $1 \%$ to N36.30 billion (4\% of THE) in 2005 (Soyibo et al, 2005) Although the international assistance to the Nigerian health sector is increasing, it still accounts for a small proportion of public health expenditures. The united states agency for international development USAID during the World Economic Forum on Africa WEFA which held in Abuja Nigeria between $7^{\text {th }}$ to $9^{\text {th }}$ may 2014, announced a US\$20 million scheme to provide affordable financing options and increase capacity in Nigeria Primary Health care system to assist in preventing child and maternal mortality (FMoH, 2014).

\section{iv.Health Insurance}

This comprise of the social insurance and community based health insurance

\section{Social Insurance}

Health Insurance is a branch of insurance business, a social device whereby financial loss is spread over so many members of the public thereby allowing healthcare delivery to be spread to the poor and the rich by payment of voluntary or compulsory premiums or contributions that they can afford since income distribution in any society is highly skewed with most people in the very low income brackets. The idea of a National Health Insurance Scheme was first considered by the authorities in 1962 but was established by Decree No 35 of 1999. The Decree states that "there is hereby established a scheme to be known as the National Health Insurance Scheme (in this Decree referred to as "the Scheme") for the purpose of providing health insurance which shall entitle insured persons and their dependants the benefit of prescribed good quality and cost effective health services as set out in this Decree". It was not until 43 years after that the sum of 26 billion Naira was set aside for the scheme in the 2005 budget. The NHIS decree statutorily allows each insured person to decide which health centre he wishes to register with. A monthly capitation is paid to the health centre from the pooled funds. Health Maintenance Organizations (HMOs) are empowered to coordinate the activities of the health centers as they dispense healthcare to the insured while the over-all regulation of the scheme rests with 
the National Health Insurance Scheme Council. The council was established by the same decree (Advocate Health, 2007).

\section{Community Based Health Insurance}

Community based health financing or community financing for health is referred to as a mechanism whereby households in a community (the population in a village, district or other geographical area, or a socialeconomic or ethnic population group) finance or co-finance the current and/or capital costs associated with a given set of health services, thereby also having some involvement in the management of the community financing scheme and organization of health services. There may also be various forms of community financing; a scheme can involve the direct payment of health services or health services inputs such as drugs, the payment of user fees for services organized via the scheme, or community based health insurance. Community health insurance is common denominator for voluntary health insurance schemes that are labeled alternatively as mutual health insurance schemes (mutual health organization, HMO) and medical aid societies or medical aid schemes. The common characteristics however are that they are run on a non-profit basis and they apply the basic principle of social health insurance. (Obansa \& Orimisan, 2013).

\section{v. Exemptions}

This is a less emphasized means of financing health care sector, Exemption is health care financing strategy whereby some vulnerable members of the community particularly under-five children and pregnant women are exempted from paying for health care services. Majority of states in the country have policies and programmes aimed at providing free Maternal and Child Health $\mathrm{MCH}$ Services. But funding level, benefit package and coverage show wide variation across states (Obansa \& Orimisan, 2013). This kind of health care financing strategy is associated with problems which includes; fraud and corruption in providing the drugs and other health care resources that are meant for the exempted people leading to short supply, some members of the community who can afford the health care services still go and compete for the few resources leading to overcrowding and ineffective health care services.

\section{Trends Of Public Health Care Finance System}

Over the years, government resources dedicated to health care are extremely low in Nigeria. According to World health Organization (WHO; 2004), private health spending represents the largest proportion of total health expenditures in Nigeria. In 2004, private out-of-pocket health expenditure was equal to nearly $70 \%$ of total health expenditure in Nigeria. Prepaid plan represent around 5\% of total health spending. Government health expenditures represent $30.4 \%$ of total health expenditure for the period. (Obansa \& Orimisan, 2013)

Federal Government capital and recurrent expenditures to the health sector between 2003 and 2007. The federal government capital expenditure on health were N6.4 billion (2.6\%) in 2003, N18.2billion (5.2\%) in 2004, N21.8 billion (4.2\%) in 2005, N32.2 billion (5.8\%) in 2006 and N41.8 billion (5.5\%) in 2007, a clear downward trend. The health sector total capital expenditure in the period 2003-2007 was 5.0\% compared with allocation to agriculture, (13.7\%), education (6.5\%), administration, (33.1\%), economic services, (47.9\%). Funding to the health sector got to its peak in 2006 after which it started to decline in subsequent years. (Obansa \& Orimisan, 2013) The Federal Government annual recurrent expenditure on health were N33.3 billion (3.4\%) in 2003, N34.2 billion (3.0\%) in 2004, N55.7 billion (4.2\%) in 2005, N62.3 billion (4.5\%) in 2006 and N89.6 billion $(5.6 \%)$ in 2007 respectively. The average percentage of recurrent expenditure in the period 2003-2007 stood at $4.3 \%$ compared with education, $(7.5 \%)$.

The total government health expenditure as a proportion of Total Health Expenditure was estimated as $18.69 \%$ in 2003, 26.40\% in 2004, and 26.02\% in 2005 (Soyibo, Olaniyan \& Lawanson, 2009). Remarkably, the federal budgetary component of health expenditure has increased over the years. It increased from $1.7 \%$ in 1991 to $7.2 \%$ in 2007 (WHO, 2009, Nigerian Health System, 2011). Nevertheless, the budgetary allocation for health is still below the $15 \%$ signed by the Nigerian government in the Abuja declaration (WHO, 2009) Nigeria's health expenditure is relatively low, even when compared with other African countries. The total health expenditure (THE) as percentage of the gross domestic product (GDP) from 1998 to 2000 was less than 5\%, falling behind THE/GDP ratio in other developing countries such as Kenya (5.3\%), Zambia (6.2\%), Tanzania (6.8\%), Malawi (7.2\%), and South Africa (7.5\%) (Soyibo, 2005).

Out-of-pockets account for the highest proportion of health expenditure in Nigeria. Out-of-pocket expenditure as a proportion of THE averaged 64.59\% from 1998 to 2002. (Soyibo, 2005).In 2003, it accounted for $74 \%$ of THE. It decreased to $66 \%$ in 2004 and later increased to $68 \%$ in 2005 (Soyibo et al, 2009). This implies that households bear the highest burden of health expenditure in Nigeria.

In terms of donor funding, the contribution of development aid to health care financing in Nigeria was estimated as N27.87 billion (4\% of THE) in 2003. This increased by $29 \%$ to N36.04 billion (4.6\% of THE) in 2004 and by just $1 \%$ to N36.30 billion (4\% of THE) in 2005 (Soyibo et al, 2005). In 2005, health insurance 
companies and firms accounted for $2 \%$ and $1 \%$ of THE, respectively (Onwujekwe, Onoka \& Uzochukwu, 2009).

The level of government expenditures in the Nigeria health sector over the years tells a story of neglect. Before the civilian government came into power in 1999, the annual government expenditures on health was \$533.6 million in 1980 after which it nose-dived, reaching a trough of \$58.8 million in 1987. By 1999, significant increases in health expenditure were noticed, reaching a peak in 2002 at $\$ 524.4$ million ( Health Reform Foundation HERFON, 2006, CBN, 2006).

\section{Challenges Of Health Care Finance Systems In Nigeria}

Achieving a successful health care financing system continues to be a challenge in Nigeria. Limited institutional capacity, corruption, unstable economic, and political context have been identified as factors why some mechanisms of financing health care have not worked effectively. (Adinma \& Adinma, 2010). Study conducted by Ichoku \& Fonta , (2009) has shown that there is a large incidence and severity of catastrophic healthcare financing in Nigeria. Furthermore, effective use of the meager financial resources available to the health sector in Nigeria remains a problem and challenge. (National Open University of Nigeria NOUN, 2007). challenges facing the public health care financing in Nigeria include;

i. Inadequate political commitment to health, leading to poor funding of health in general, and Primary Health Care in particular.

ii. Gaps in the area of stewardship and governance as evidenced by lack of clarity of the role of government, at all levels in financing health care.

iii. Inadequate or non implementation of health policy that clearly spells out how funds are to be allocated and spent in the health sector.

iv. Governance issues with the NHIS and poor buy-in by the states limit coverage.

v. Dominance of Out of Pocket payments presents possibilities of under/oversupply of services depending on financial abilities.

vi. Non exploitation of other sources of health financing

vii. Several stakeholders, including development partners finance health independently and not in accordance with governments' policy thrust. This has led to inefficient use of scarce resources and duplication of efforts.

\section{Solutions To Challenges Of Health Care Finance System In Nigeria}

The Federal Government should explore and improve other sources of financing that are efficient, equitable, fair and sustainable (Federal Republic of Nigeria FRN, 2006). According to Ejughemre (2014) there is evidence that the private sector could be a key player in delivering health services and impacting health outcomes, including those related to healthcare financing.

Increased funding to the health sector, government should massively increase investment and public spending on health to at least $15 \%$ of its budget as signed by the Nigerian government at the Abuja declaration. Despite the variety of financing sources, the level of health spending is relatively low. Nigeria spends less than $5 \%$ of her gross domestic product (GDP) on health and per capita health spending is slightly lower than US\$35 per person per year. At a minimum, per capita health spending must increase to $\$ 60$ in order to provide a minimum range of services.

Also, government should strive to promote the development of industries and relevant manpower to enhance local capabilities in the production of drugs, including Anti Retro Viral and laboratory reagents, medical equipment and spare parts to improve supplies and maintenance capabilities so as to reduce cost and improve efficiency.

Furthermore, there should be a ban on the financing of government officials going overseas for medical treatment. Better mind-sets and behavior, Pay-for- performance bonuses and other incentive programs would motivate health workers to provide high-quality care efficiently. Prudent management of the scarce funds will go a long way in changing the Nigerian health care financing situation. To achieve this, the Federal Ministry of Health will need to provide strategic, progressive leadership. A leadership that is willing to discard failed and tired structures, systems and indeed individuals. (Obansa \& Orimisan, 2013)

Effective monitoring and evaluation (M\&E) of performance and tracking the use of resources, health policies and reforms. Implementation of health financing policies and actions need to be monitored and evaluated at regular intervals. The current WHO agreements on intellectual property rights, which effectively limit the access of the poor countries to essential medicines and cheap drugs, must also be opposed by the governments and people of the poor countries (Chike, 2006).

Nigerian policy makers should pay closer attention to the health sector by increasing its yearly budgetary allocation to the sector. Nevertheless the key to good results lies not in ordinarily increasing particular budgetary allocation but rather in implementing a public finance system that, to the extent possible, links 
specific expenditure and revenue decisions and ensure the usage of the allocated fund as transparently as possible (bakare and olubukun, 2011). More funds should be set aside for training and retraining of health workers so that they can be more efficient and more workers (labour) should be recruited into the health sector so as to bring about growth not only in the sector but in the whole economy. Some strategies to tackle health sector challenges in Nigeria may include improved access to primary healthcare; strategic and purposeful leadership in health delivery services; increasing funding to the health sector; amongst others (Obansa \& Orimisan, 2013)

\section{Conclusion}

The health of any nation is a very vital to the development of that country, therefore, for any country to develop then the health care sector must adequately funded. The way health care is financed varies across different countries. Nigeria finance its public health care through tax revenue (by the federal, state and local government), out of pocket payments (also refers to as user fees), donor funding and health insurance. An overview of reviewed literatures indicates that a greater percentage of public health care financing in Nigeria comes from house hold in the form of out-of-pocket payments while the total government health expenditure out of the total health expenditure is estimated as just $18.69 \%$ in $2003,26.40 \%$ in 2004 , and $26.02 \%$ in 2005 (Soyibo, Olaniyan \& Lawanson, 2009). The Nigerian public health care sector is faced with a lot of challenges ranging from inadequate funding, financing policies and inadequate management of the scarce resources. It is therefore recommended that government should massively increase investment and funding to at least $15 \%$ of its annual budget on public health as signed at the Abuja declaration, effective monitoring and evaluation of the utilization of funds, encouraging local production of drugs and other necessary requirements of the health sector, increase funds for training and research amongst health workers and discourage use of public funds for people to travel abroad for medical services. This is to encourage will encourage the use of such funds in developing the country's health sector.

\section{References}

[1]. Adinma, E. D. \& Adinma, B. J. (2010). Community based healthcare financing: An untappedoption to a more effective healthcare funding in Nigeria. Niger Med 51:95-100.

[2]. Advocate Health (2007). Health care Financing in the developing world: is Nigeria's healthinsurance scheme a viable option? ADVOCATE HEALTH. 2007

[3]. Agbatogun, K. K. \& Taiwo, A. S. (2010). Determinants of Health expenditure in Nigeria. Journalof research in National development. 8(2).

[4]. Bakare, A. S. \& Olubukun (2011). Health care expenditure and economic growth in Nigeria: An empirical study. Journal of Emerging Trends in Economics and ManagementSciences.(JETEMS). 2(2): 83-87.

[5]. Carrin, G., Evans, D. \& Xu, k.(2007) Designing health financing policy towards universalcoverage. Bull World Health Organ 2007;85:652.

[6]. Centra Bank of Nigeria CBN (2005). “Annual Reports and Statement of Accounts”. CBN Reports, 2000, 2001, 2002, 2003 as quoted in World Bank Country Report for Nigeria,2005.

[7]. Chike I, (2006) "Nigeria Health Sector Reforms: Rhetoric or Real?" Nigeriaworld Onlinenewspaper, Thursday, June 22.

[8]. Curran, C. R. \& Totten, M. K. (2010). Expanding the role of Nursing in Health care governance.Nursing economics. 28(1).

[9]. Ejughemre, U. J. (2014). Accelerated reforms in Health care financing: the need to scalp up private sector participation in Nigeria. International journal of health policy and management. 4(1): 13-19

[10]. Federal Ministry of Healh FMoH (2014). USAID, Nigeria announces US $\$ 20$ assistance to prevent child, maternal mortality. World Economic Forum on Africa WEFA $7^{\text {th }}$ to $9^{\text {th }}$ may 2014 . Abuja Nigeria.

[11]. Federal Republic of Nigeria (2004). "Health sector Reform Programme Strategic thrusts with a logical framework and a plane of action 2004-2007" (Sept).

[12]. Health Reform Foundation HERFON, (2006) "Nigeria Health Review”, Health Reform Foundation of Nigeria, Kenbim press Ltd, Ibadan. Pg10-12,130,19.

[13]. Ichoko, H. E. \& Fonta, W. M. (2009). Catastrophic health care financing and poverty: empirical evidence from nIgeria. Journal of social and economic development. 11(2).

[14]. Lagarde, M. \& Palmer, N. (2006) Evidence from Systematic Reviews to Inform Decision Making Regarding Financing Mechanisms That Improve Access to Health Services for Poor People: A Policy Brief Prepared for the International Dialogue on Evidence Informed Action to Achieve Health Goals in Developing Countries (IDEAHealth) in Khon Kaen; Thailand. 13-16 December 2006. Geneva: Alliance for Health Policy and systems Research; 2006.

[15]. National Health Insurance scheme (2011). Retrieved on jun $10^{\text {th }} 2011$ from: http://www.nhis.gov.ng/.

[16]. National Open University of Nigeria NOUN (2007). Health Economics. Lagos. National Open University of Nigeria. 4(1)

[17]. Nigerian Health system.[Online].retrieved on April $27^{\text {th }} 2011 \mathrm{from} \quad$ http://www.who.int/pmnch/countries/nigeria-planchapter-3.pdf.

[18]. Obansa, S. A. J. \& Orimisan, A. (2013). Health care financing in Nigeria: prospects and challenges. Mediterranean journal of social sciences. 4(1).

[19]. Olakunde, B.O. (2012) Public health care financing in Nigeria. Which way forward? Ann Nigeria Med. 6 (1): 4-10

[20]. Onwujekwe, O., Onoka, C. \& Uzuchukwu, B. (2009). Is community based health insurance equitable strategy for paying for health care? Experiences from southeast Nigeria. Health policy. 92. 96-102

[21]. Palmer, N., Mueller, D.H., Gilson, L., Mills, A. \& Haines, A. (2004) Health financing to promote access in low income settings How much do we know? PUBMED 364:1365-70.

[22]. Savedoff W. Tax-based financing for health system: Options and experiences. Geneva: WHO; 2004.

[23]. Sekhri, N. \& Savedoff, W. (2004) Private Health Insurance Implication for Developing Countries. Geneva: World Health Organization; 2004. 
[24]. Soyinbo, A. (2005) National Health Accounts of Nigeria 1999-2002. Final report submitted to World Health Organization. Ibadan: University of Ibadan;

[25]. Soyibo, A., Olaniyan, O. \& Lawanson, A. O. (2009) National Health Accounts of Nigeria 2003 2005: Incorporating Sub-National Health Accounts of States. Main report submitted to Federal Ministry of Health. Ibadan: University of Ibadan; The Nigerian Academy of Science (2009). Effective primary health care in Nigeria. Lagos. West African Publishers Limited.

[26]. United Nations Development Programme. UNDP (2011). MDGs Needs Assessment and Financing Strategy for Nigeria: Policy Brief. [Online]. Retrieved on July $8^{\text {th }} 2011$ from http://www.ng.undp.org/mdgs/policy_brief.pdf.

[27]. United Nations Population Fund UNFPA (2010), Health System strengthening. Retrieved on may $24^{\text {th }} 2014$ from http/:www.nigeria.unpfa.org/

[28]. Uzochukwu, B. S. C. (2012). Health care financing: a review of the Nigerian situation. Health Reform Foundation HERFON meeting 24-26 march

[29]. World Health Organization WHO (2004) 'Regional Overview of Social Health Insurance in South-East Asia WHO/AFRO (1999) "Strategic Health Research Plan (1999-2003) for the WHO Africa Region. WHO/Regional Committee for Africa Resolution $\mathrm{AFR} / \mathrm{RC} 48 / \mathrm{R} / 4$.

[30]. Harare World Bank. Improving Primary Health Care Delivery in Nigeria Evidence from Four States. Working paper No 187. Washington DC: World Bank; 2010.

[31]. World Health Oranization. WHO (2009).Country Cooperation Strategy: Nigeria 2008-2013. Brazzaville:WHO Regional office for Africa; 2009. 